\title{
Endoscopic band ligation plus single-incision needle knife biopsy for small subepithelial deep-layer tumor: easy and effective
}

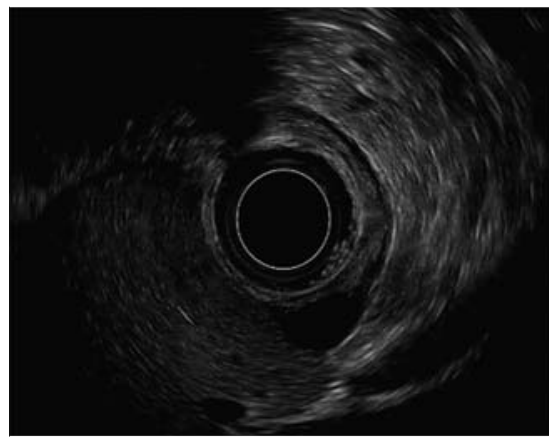

- Fig. 1 Endoscopic ultrasound view of a small gastric subepithelial tumor, seen fortuitously during a diagnostic process for iron-deficiency anemia.

A 61-year-old man was referred for an iron-deficiency anemia diagnostic process. Upper gastrointestinal endoscopy was performed and fortuitously revealed a small gastric subepithelial lesion. Endoscopic ultrasound (EUS) characterization revealed a solid lesion, with fusiform morphology, well-defined by smooth edges and an hypoechoic homogeneous internal pattern, measuring $12.3 \times 5.8 \mathrm{~mm}$, and originating in the muscularis propria layer, which confirmed a subepithelial tumor ( $\triangleright$ Fig. 1). With the aim of avoiding EUS surveillance of the subepithelial tumor, a minimally invasive removal technique was planned [1-3].

Endoscopic band ligation of the subepithelial tumor was done using a Captivator endoscopic mucosal resection standard gastroscope device (Boston Scientific, Quincy, Massachusetts, USA) combined with a single-incision needle knife (SINK) biopsy (XL Triple-lumen needle knife; Boston Scientific; and pure-cut 90-W, Beamer CE600; ConMed, Utica, New York, USA). A standard videogastroscope was used, and four biopsy samples were obtained (Radial Jaw large capacity biopsy forceps; Boston Scientific) ( $>$ Fig. 2). The patient remained in hospital for 24 hours and was called at
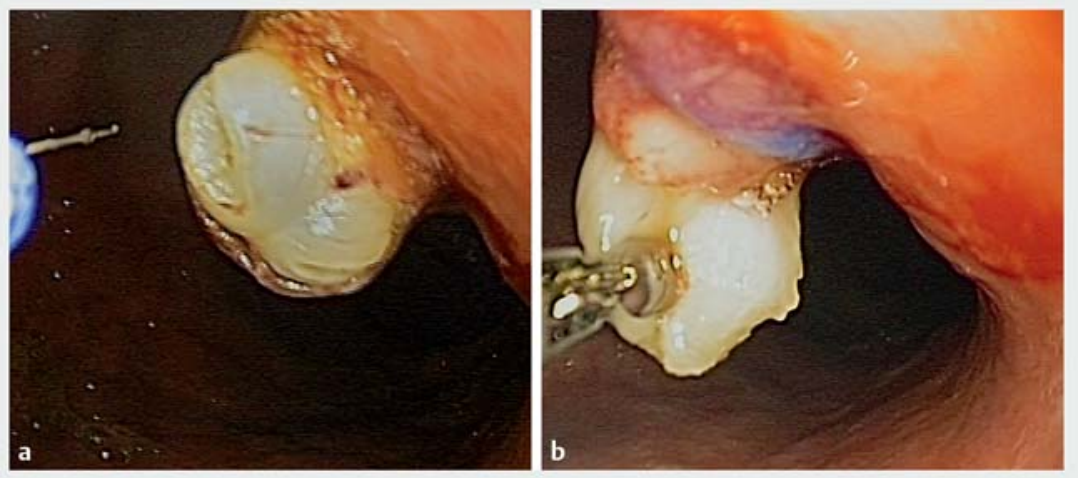

- Fig. 2 a Subepithelial tumor: endoscopic view of single-incision needle knife (SINK) biopsy. b Use of biopsy forceps to obtain samples for anatomopathological study.

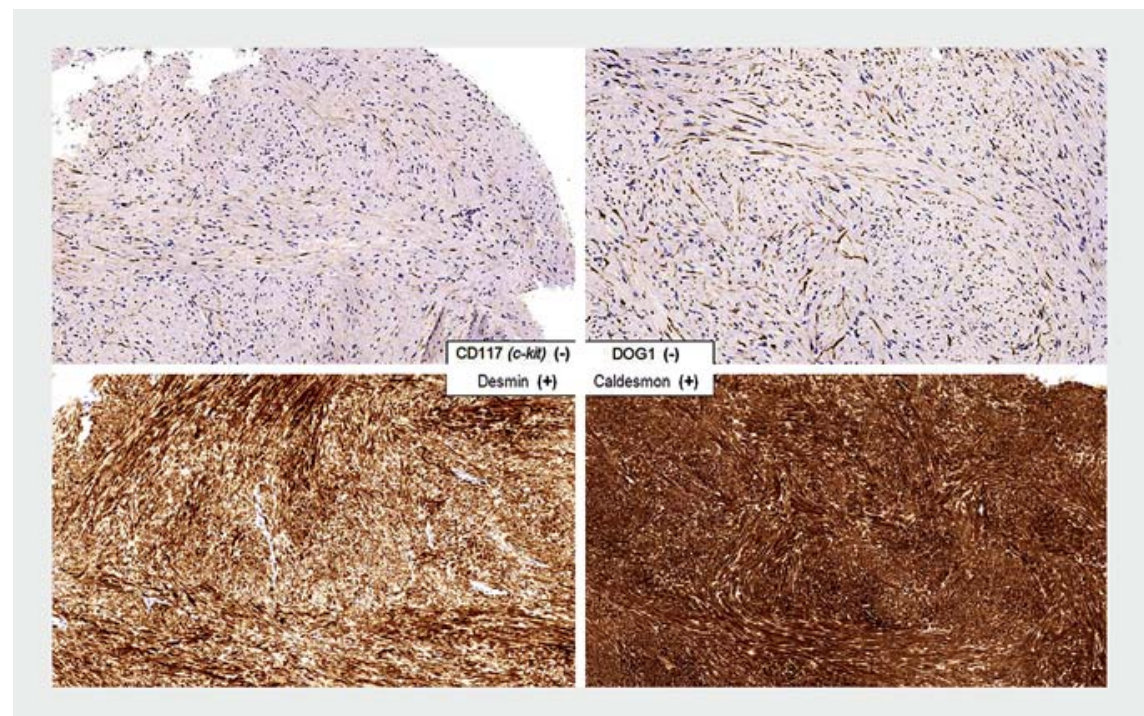

- Fig.3 Immunohistochemistry markers confirming a leiomyoma.

48 hours and 7 days after the procedure, with no incidents or adverse events being reported ( $\downarrow$ Video $\mathbf{1}$ ).

Pathological and immunohistochemistry examination revealed a fascicular proliferation of fusiform eosinophilic cells, negative for CD117 (c-kit) and DOG1, and positive for desmin and caldesmon, corresponding to the diagnosis of a leiomyoma (> Fig. 3 ).
The first EUS control, at 5 weeks after the procedure, revealed a complete disappearance of the subepithelial tumor features, showing a discreet eschar (simple biopsy with 4 samples, showing normal gastric mucosa). Long-term EUS control at 1 year showed that the subepithelial tumor had vanished, confirming the successful result and allowing discontinuation of endoscopic surveillance ( $\mathbf{F i g . 4 )}$ ). 


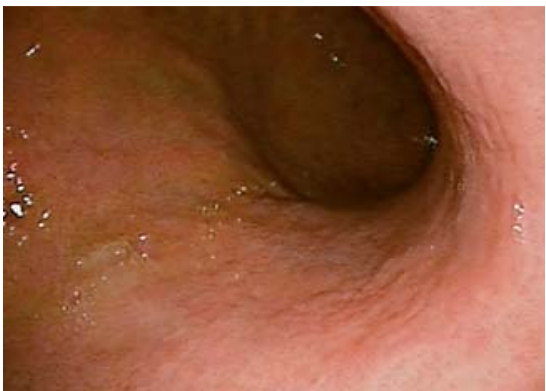

> Fig. 4 Endoscopic view of gastric wall 1 year after the procedure, showing no sign of the subepithelial tumor.
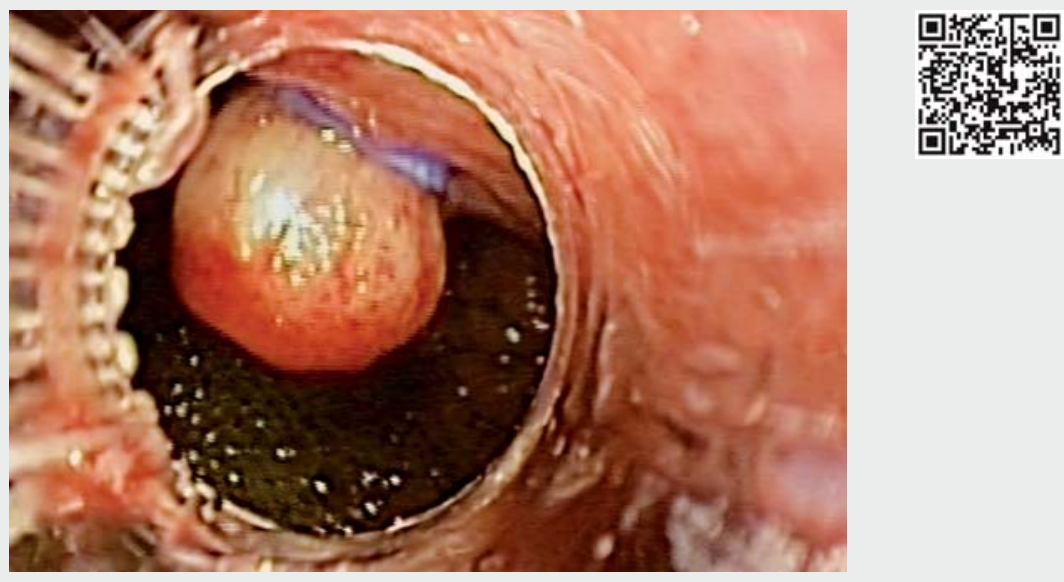

Video 1 Endoscopic band ligation without resection, plus single-incision needle knife biopsy, for a gastric subepithelial tumor.

\section{Corresponding author} SINK biopsy seems to be an effective minimally invasive technique that is safer than endoscopic resection for treating a gastric subepithelial tumor originating in the muscularis propria $[4,5]$.

Endoscopy_UCTN_Code_TTT_1AO_2AG

Competing interests

None

The authors

Francesc Bas-Cutrina ${ }^{1}$, Claudia F. Consiglieri ${ }^{1}$, Jan Bosch-Schips ${ }^{2}$, Joan B. Gornals ${ }^{1,3}$

1 Endoscopy Unit, Department of Digestive Diseases, Hospital Universitari de BellvitgeIDIBELL, University of Barcelona, Catalonia, Spain.

2 Department of Pathological Anatomy, Hospital Universitari de Bellvitge-IDIBELL, University of Barcelona, Catalonia, Spain.

3 Faculty of Health Sciences, Universitat Oberta de Catalunya, Barcelona, Catalonia, Spain

\section{Joan B. Gornals, MD, PhD}

Endoscopy Unit, Department of Digestive Diseases, Hospital Universitari de BellvitgeIDIBELL (Bellvitge Biomedical Research Institute), Feixa Llarga s/n, 08907

L'Hospitalet de Llobregat, Barcelona, Catalonia, Spain Fax: +34-93-2607681

jgornals@bellvitgehospital.cat

\section{References}

[1] Faulx AL, Kothari S, Acosta RD et al. The role of endoscopy in subepithelial lesions of the Gl tract. Gastrointest Endosc 2017; 85: $1117-1132$

[2] Arezzo A, Verra M, Miegge A et al. Loop-andlet-go technique for a bleeding, large sessile gastric gastrointestinal stromal tumor (GIST). Endoscopy 2011; 43: E18-19

[3] Binmoeller KF, Shah JN, Bhat YM et al. Suckligate-unroof-biopsy by using a detachable 20-mm loop for the diagnosis and therapy of small subepithelial tumors (with video). Gastrointest Endosc 2014; 79: 750 - 755

[4] Hwang JH, Konda V, Abu Dayyeh BK et al. Endoscopic mucosal resection. Gastrointest Endosc 2015; 82: 215-226

[5] Zang D, Lin Q, Shi R et al. Ligation-assisted endoscopic submucosal resection with apical mucosal incision to treat gastric subepithelial tumors originating from the muscularis propria. Endoscopy 2018; 50: 1180 1185

\section{Bibliography}

DOI https://doi.org/10.1055/a-0875-3958

Published online: 12.4.2019

Endoscopy 2019; 51: E191-E192

(c) Georg Thieme Verlag KG

Stuttgart · New York

ISSN 0013-726X

\section{ENDOSCOPY E-VIDEOS \\ https:/|eref.thieme.de/e-videos}

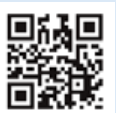

Endoscopy E-Videos is a free access online section, reporting on interesting cases and new techniques in gastroenterological endoscopy. All papers include a high quality video and all contributions are freely accessible online.

This section has its own submission website at https://mc.manuscriptcentral.com/e-videos 